\title{
Constitutive model for soft rocks considering structural healing and decay
}

\section{AUTHOR(S):}

Kikumoto, Mamoru; Nguyen, Vu Pham Quang;

Yasuhara, Hideaki; Kishida, Kiyoshi

\section{CITATION:}

Kikumoto, Mamoru ...[et al]. Constitutive model for soft rocks

considering structural healing and decay. Computers and Geotechnics 2017, 91: 93-103

\section{ISSUE DATE:}

2017-11

URL:

http://hdl.handle.net/2433/226599

\section{RIGHT:}

(c) 2017. This manuscript version is made available under the CC-BY-NC-ND 4.0 license

http://creativecommons.org/licenses/by-nc-nd/4.0/; The full-text file will be made open to the public on 1 November 2019 in accordance with publisher's 'Terms and Conditions for Self-Archiving'.; この論文は出版社版でありません。引 用の際には出版社版をご確認ご利用ください。; This is not the published version. Please cite only the published version. 
1

2

3 Mamoru Kikumoto $^{1^{*}}$, Nguyen Pham Quang $\mathrm{Vu}^{2}$, Hideaki Yasuhara ${ }^{3}$, and Kiyoshi Kishida ${ }^{4}$

$4{ }^{1}$ Department of Civil Engineering, Yokohama National University, Japan,

$5 \quad$ kikumoto@ynu.ac.jp

$6 \quad{ }^{2}$ Department of Civil Engineering, Yokohama National University, Japan, nguyen-vu-

7 hr@ynu.jp

$8{ }^{3}$ Department of Civil and Environmental Engineering, Ehime University, Japan, $9 \quad$ yasuhara.hideaki.me@ehime-u.ac.jp

${ }^{4}$ Department of Urban Management, Kyoto University, Japan, kishida.kiyoshi.3r@kyotou.ac.jp

${ }^{*}$ Corresponding author

\section{Abstract}

The behavior of soft rock depends on the contact area between mineral particles and the tensile strength of the interparticle cementation, which are usually referred to as structures. We investigated the effects of structural decay and healing on the behavior of soft rock through monotonic and slide-hold-slide triaxial tests under the drained condition with constant effective confining pressure. We developed a constitutive model for soft rocks incorporating structural healing and decay in the context of the extended critical state theory. The model was validated via laboratory tests and captured the behavior of soft rock, including the healing and decay phenomena.

24 Keywords: soft rock, rock structure, slide-hold-slide triaxial test, healing, decay, critical state theory

\section{Introduction}


In soft rock, mineral particles consist of aggregates of microcrystals formed by ionic, atomic, or molecular bonding, and these mineral particles are usually cemented or adhered mutually at the interparticle contact interfaces [1]. Thus, the stiffness and strength of the soft rock will depend primarily on the contact area between mineral particles and the tensile strength of interparticle cementation, which are usually referred to as rock structures.

The effects of the decay of the structures of soft rocks have been studied extensively. For example, the effects of the rock structures on the stress-strain characteristics have been investigated via laboratory experiments such as oedometer tests on Culebra shale [2], onedimensional compression tests on chalk [3] and tuff [4, 5], and monotonic triaxial compression tests on calcarenite and tuff [6]. Leroueil and Vaughan [7] and Kavvdas [8] discussed the effects of structures on the strength and stiffness of natural soils and weak rocks, and pointed out the similarities in behavior between natural soils and soft rocks.

Shao and Henry [9] have developed an elastoplastic model for porous rocks by extending a model for sands [10], and they have predicted the behavior of porous chalk. Gens and Nova [11], Kavvdas et al. [12], Adachi and Oka [13], and Lagioia and Nova [14], among others, have also proposed constitutive models for various types of weak rocks such as mudstones, claystones, marls, shales, tuffs, weak limestones, and weak sandstones, and validated their simulation through comparison with a series of laboratory tests. The common features of the constitutive models for soft rocks are: (a) the models are formulated by extending the original models for unstructured geomaterials; (b) the structure of the weak rock is assumed to be destroyed due to the breakage of the interparticle cementation during loading.

Meanwhile, Dieterich and Kilgore [15] indicated that the contact area of the solid interface increases over a period of time, and that frictional resistance arises from the development of the contact area. It is reasonable to expect that a similar mechanism exists in the contacts between the mineral particles of soft rock at a microscopic level. Thus, we presume that the structure of soft rocks will recover to some extent after the loading process. 
55

56

This leads to an increase in the stiffness and strength of soft rocks during the hold phase. Though a number of models [9,11, 12, 13, and 14] have considered the effects of structural decay, the healing effect of the structure over time has not been considered.

Thus, it is crucial to consider both the effects of structural healing as well as structural decay in constitutive models, especially when estimating the long-term behavior of soft rocks. Therefore, the objective of the current study was to consider the effects of both structural healing and decay on the behavior of soft rocks. We first conducted triaxial tests on soft sedimentary rock with repeated slide-hold-slide (SHS) processes to observe the effects of structural healing and decay on the strength and stiffness of soft rock. After the slide-holdslide processes, we investigated the effect of time on the structural recovery of soft sedimentary rock. We then developed a constitutive model that considered the effects of both structural healing and decay of soft rocks. In our model, the critical state theory was extended to consider the effect of the rock structure. Moreover, the subloading surface concept [16] was incorporated into the model to appropriately consider the combined effects of density and structure. The healing and decay of the structure was modeled using a newly introduced state variable and evolution law. The model was finally validated via monotonic and slide-holdslide triaxial tests under drained condition.

\section{Slide-Hold-Slide Triaxial Tests}

We conducted consolidated, drained triaxial compression tests with multiple SHS processes on soft sedimentary rock to observe the effects of structural healing and decay on the stressstrain characteristics. The tests were performed under three types of effective confining pressures, where several holding time periods were applied. The experimental results were used to develop and validate a constitutive model for describing the fluctuation of the rock structure.

\subsection{Test overview}


81 The SHS triaxial tests were conducted on saturated cylindrical specimens of a pumice lapilli

82 tuff, a type of soft volcanic sedimentary rock. The rock specimen was a porous vesicular rock

83 primarily consisting of pyroclastic materials such as pumice. Photomicrographs of the specimen are shown in Figure 1. The modal composition of the specimen is measured by a method of point-counting and the sample consists of $85.0 \%$ natural glassy mineral $(39.0 \%$ of Celadonite, $32.75 \%$ of Zeolite and $12.75 \%$ of Montmorillonite) and $15.0 \%$ of crystal and lithic spall (7.0 \% of Plagioclase, $5.75 \%$ of Quartz and $2.25 \%$ of Lithic). To measure the volumetric behavior of the specimens accurately, achieving the saturation of the specimens with water is essential. For this, water-soluble carbon dioxide $\left(\mathrm{CO}_{2}\right)$ gas is first percolated through the sample, followed by flushing with de-aired water. Backpressure is applied to improve the saturation during the tests.

The experiments were conducted using the apparatus shown in Figure 2 under consolidated, drained conditions. The temperature was kept constant at $20{ }^{\circ} \mathrm{C}$ throughout the test to ensure that thermal effect on the specimen were negligible. First, an isotropic consolidation path was applied until the predetermined effective confining stress $\sigma_{r}{ }^{\prime}$ of 300 and $700 \mathrm{kPa}$ was reached. The specimen was then sheared under drained condition with a constant effective confining pressure. The constant axial strain rate of $0.01 \% / \mathrm{min}$ was applied precisely by a screw jack until the post-peak phase, where the stress state approached the residual state. The holding process was then applied by maintaining a constant axial strain under various holding time periods from 60-241200 s. The holding process was always followed by the re-shearing process. 

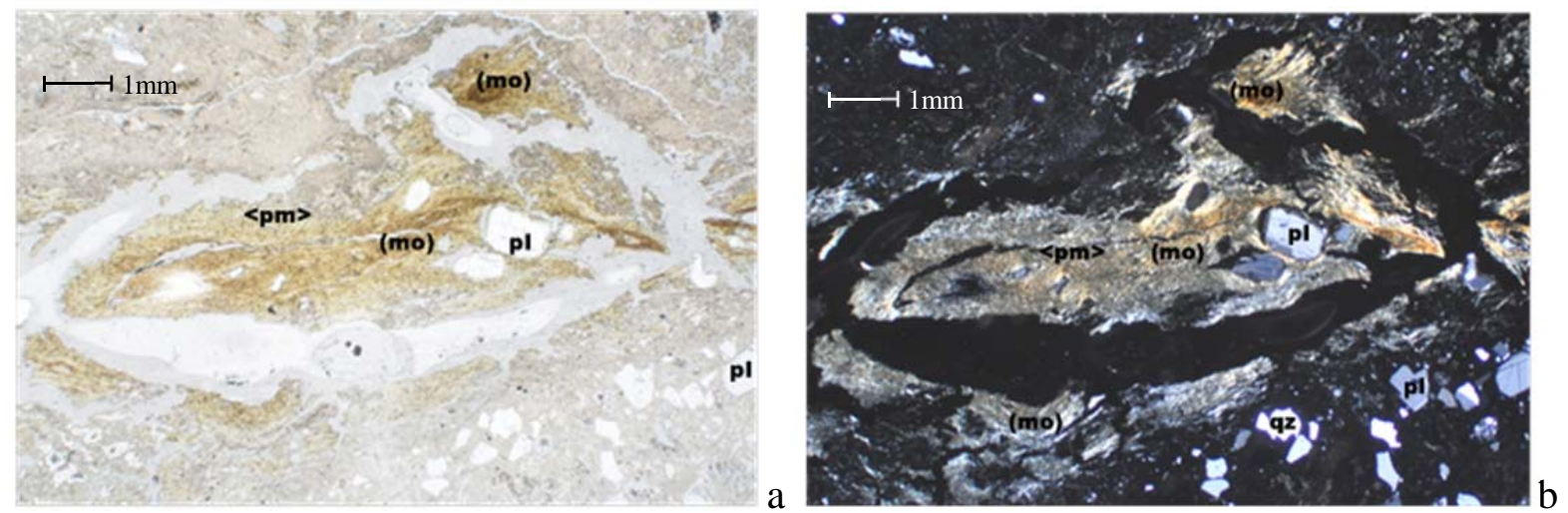

Figure 1: Photomicrographs of pumice lapilli tuff (magnification x15; qz: quartz, pl:

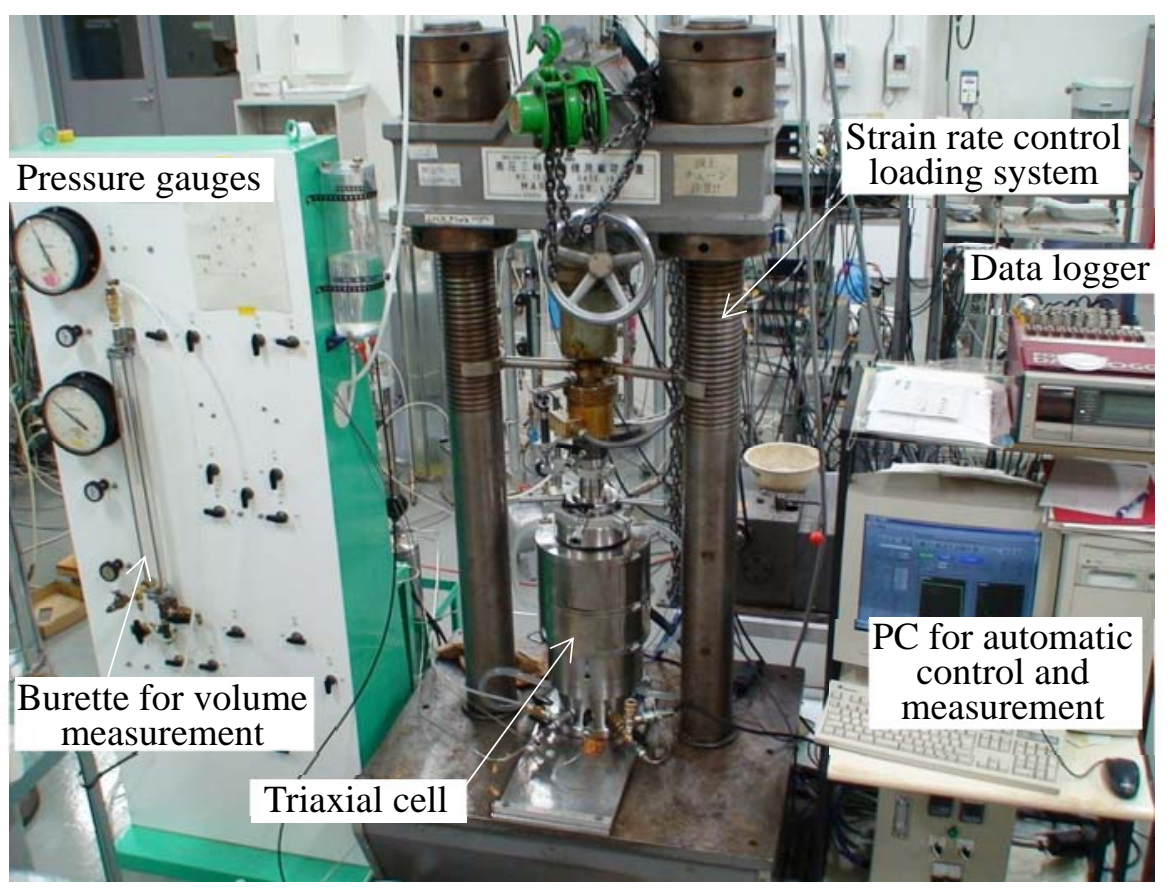

Figure 2: Triaxial testing apparatus.

\subsection{SHS triaxial test results}

112 Examples of the SHS triaxial test results are shown in Figures 3 and 4 with applied effective confining stresses $\sigma_{r}$ of $300 \mathrm{kPa}$ and $700 \mathrm{kPa}$, respectively. From the stress-strain relationship in the initial stage of shearing, a relatively high stiffness was exhibited, and an apparent peak stress was observed in the beginning stage of shearing. After the peak strength, 
strain softening with positive dilatancy was observed and the stress finally reached the

117 residual strength. The specimen exhibited the typical stress-strain behavior of soft 118 sedimentary rocks, and these results appeared consistent with previous experimental observations (e.g., Adachi and Ogawa [17]). Enlarged views of the relationship between the axial strain $\varepsilon_{a}$ and the deviator stress $q\left(=\sqrt{\frac{3}{2} \boldsymbol{s}: \boldsymbol{s}}=\sqrt{\frac{3}{2}\left\{\boldsymbol{\sigma}: \boldsymbol{\sigma}-\frac{1}{3}(\operatorname{tr} \boldsymbol{\sigma})^{2}\right\}}\right)$ during the SHS process are shown in Figures 3(b) and 4(b). During the holding process in which the axial strain is held constant, stress relaxation with a reduction of the deviator stress could be observed. In the ensuing re-sliding process, the deviator stress increased with a high stiffness, reaching a peak value and then returning to the residual value. The magnitude of the strength recovery depended on the duration of the holding process, as the higher peak strength was particularly seen after a longer holding period. According to the experimental results at different confining pressures (300 and $700 \mathrm{kPa}$ ), strength recoveries could be observed after some of the longer holding periods. Such strength recoveries are considered to be a result of the healing of the rock structure. An example of the specimens after the SHS triaxial shearing is shown in Figure 5, which clearly shows a shear band formation. We expected the interparticle cementation to be destroyed due to the shear band formation during the first shearing process; then the rock structure recovered with the increase in the real area of the interparticle contact surfaces.
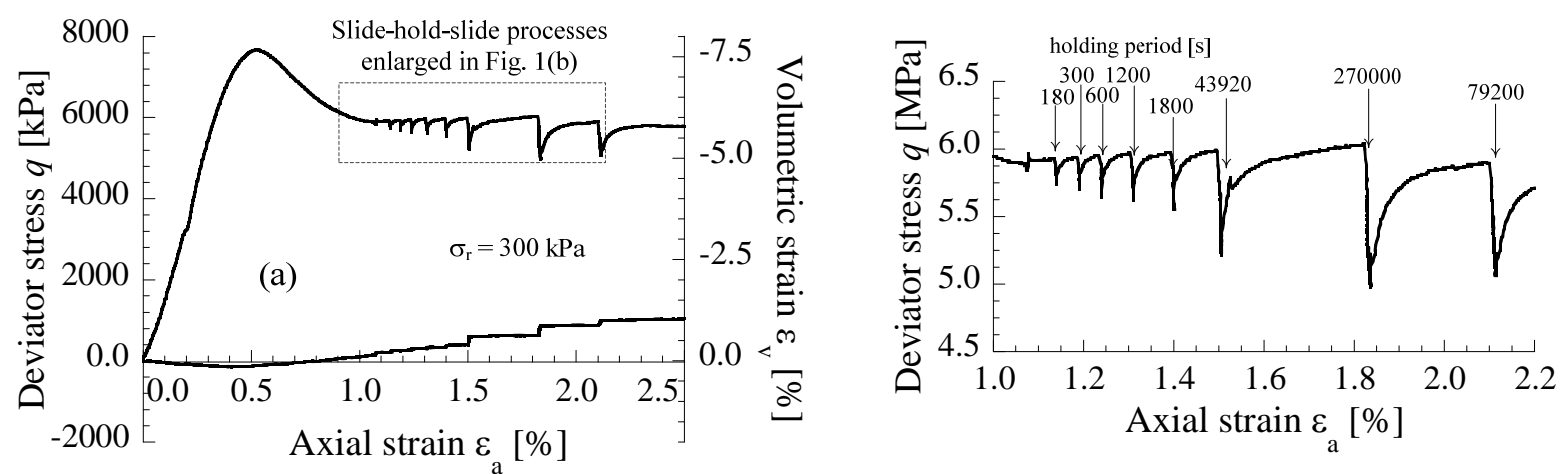

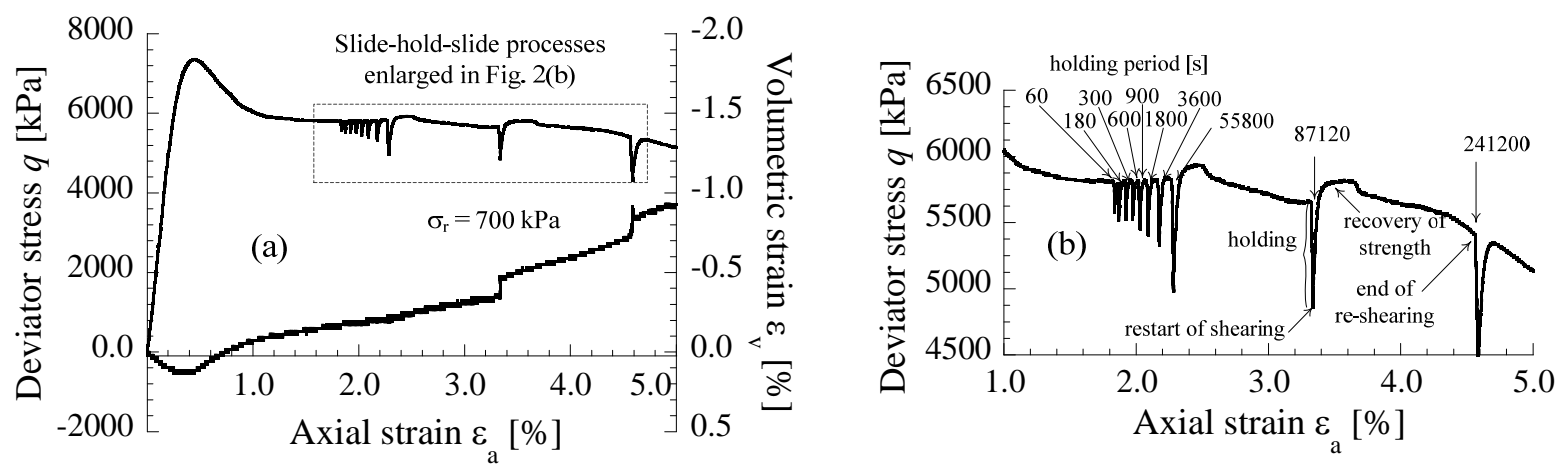

140 strain relationship at small strains and brittle failure at large strains) at low stresses; while it

Figure 4: Stress-strain relationship in the SHS triaxial test $\left(\sigma_{r}=700 \mathrm{kPa}\right):(a)$ Overall view;

(b) Enlarged view.

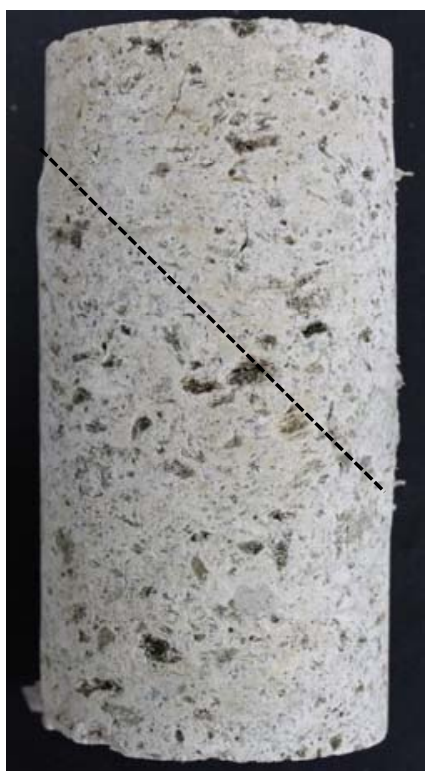

Figure 5: Photo of specimen after the SHS triaxial CD tests (effective confining stress $\sigma_{r}$ of $700 \mathrm{kPa})$.

\section{Elastoplastic model for soft rocks considering structural healing and decay}

Pellegrino [6] conducted triaxial compression tests on soft rocks such as calcarenite and tuff, and indicated that the soft rocks show a typical brittle behavior (approximately linear stressshows typically ductile behavior at higher stresses (nonlinear elastoplastic behavior and 
152 ductile failure). Novello [18] compared the behaviors of soils, soft rocks, and hard rocks in 153 triaxial tests and argued that the brittle-ductile transition due to the increase in confining 154 pressure in rocks was similar to the transition from overconsolidated to normally consolidated behavior in soils. Such a similarity in the behaviors of soft rocks and soils under different levels of confining pressure has also been confirmed by Hicher et al. [19]. In this regard, the critical state framework $[10,20]$ could be broadly applied to various geomaterials. Several extended versions of critical state models have been proposed for describing the behaviors of structured geomaterials such as structured soils [20] or soft sedimentary rocks [7]. However, the effect of healing of the rock structure has not been considered. Herein, we formulate a novel elastoplastic model based on the critical state theory [10, 20] for predicting the longterm behavior of soft rocks, including the effects of healing and decay phenomena on the rock structure.

First, we assumed an additive decomposition of the total strain rate tensor as

$$
\dot{\varepsilon}=\dot{\varepsilon}^{\mathrm{e}}+\dot{\varepsilon}^{\mathrm{p}} \#(1)
$$

165

where $\dot{\boldsymbol{\varepsilon}}^{\mathrm{e}}$ and $\dot{\boldsymbol{\varepsilon}}^{\mathrm{p}}$ are elastic and plastic strain rate tensors, respectively.

\subsection{Elastic stress-strain relationship}

For the elastic stress-strain relationship, we assumed a conventional, nonlinear elastic bulk modulus $K$ given by

$$
K=\frac{v_{0}}{\kappa} p^{\prime} \#(2)
$$

where $v_{0}$ is the initial specific volume, $\kappa$ is the swelling index that represents the slope of the elastic volumetric relationship in the semi-logarithmic $\ln p^{\prime}-v$ plane, and $p^{\prime}$ is the mean effective stress given by $p^{\prime}=\frac{\operatorname{tr} \boldsymbol{\sigma}^{\prime}}{3}$, where $\boldsymbol{\sigma}^{\prime}$ is the Cauchy effective stress tensor. We assumed that Poisson's ratio $v_{\mathrm{e}}$ was constant. Thus, the rate form of the elastic relationship was given by

$$
\dot{\sigma}^{\prime}=D^{e}: \dot{\varepsilon}^{\mathrm{e}}=D^{e}:\left(\dot{\boldsymbol{\varepsilon}}-\dot{\boldsymbol{\varepsilon}}^{\mathrm{p}}\right) \#(3)
$$




$$
D^{e}=K \mathbf{1} \otimes \mathbf{1}+2 G\left(I-\frac{1}{3} \mathbf{1} \otimes \mathbf{1}\right) \#(4)
$$

where $G$ is the shear modulus:

$$
G=\frac{3 K\left(1-2 v_{\mathrm{e}}\right)}{2\left(1+v_{\mathrm{e}}\right)}
$$

176

177

\subsection{Yield function for soft rocks considering structural healing and decay}

The critical state is the ultimate condition approached by all states of rock when the rock is sheared. The critical state line (CSL) is chosen to be linear in a semi-logarithmic compression plane, which is the specific volume $v(=1+e)$ versus the logarithm of the mean effective stress $\ln p^{\prime}$. Similar to the $C S L$, the limiting isotropic compression line (LICL) is a reference line over the $C S L$ in the $v$-ln $p$ ' plane, which any state of rock approaches under isotropic compression. A state boundary surface, which defines the upper limit of the specific volume in stress-specific volume space above which no state of soft rock can exist, has been utilized in the formulation of the critical state model [18]. This surface contains $C S L$ and $L I C L$ in the space of $v$, $\ln p^{\prime}$, and $\zeta(\eta)$, which is a function of stress ratio $\eta$, (Figure 6). The specific volume $v_{\text {sbs }}$ on the state boundary surface, which defines the least dense state of rock at stress $(p, \eta)$, is given by considering the combined effects of compression and dilation:

$$
v_{\mathrm{sbs}}=N-\lambda \ln \frac{p^{\prime}}{p_{\mathrm{a}}}+(\Gamma-N) \zeta(\eta) \#(6)
$$

where $\eta(=q / p)$ is the stress ratio, $q$ is the deviator stress, $p_{a}(=98 \mathrm{kPa})$ denotes atmospheric pressure, $\lambda$ is the compression index, and $\zeta(\eta)$ is a monotonic increasing function of stress ratio $\eta$ satisfying $\zeta(0)=0$ on $L I C L$ and $\zeta(M)=1$ on $C S L$. Here, $N$ and $\Gamma$ represent specific volumes on $\operatorname{LICL}(\eta=0)$ and $C S L(\eta=M)$ at $p^{\prime}=p_{a}$, respectively. Different functions of $\zeta(\eta)$ have been used for different versions of critical state models. In the current model, $\zeta(\eta)$ is defined in accordance with the modified Cam clay [20]:

$$
\zeta(\eta)=\frac{\ln \left\{1+\left(\frac{\eta}{M}\right)^{2}\right\}}{\ln 2} \#(7)
$$

where $M$ is the critical state stress ratio (= $\eta_{\mathrm{cs}}$ ). 


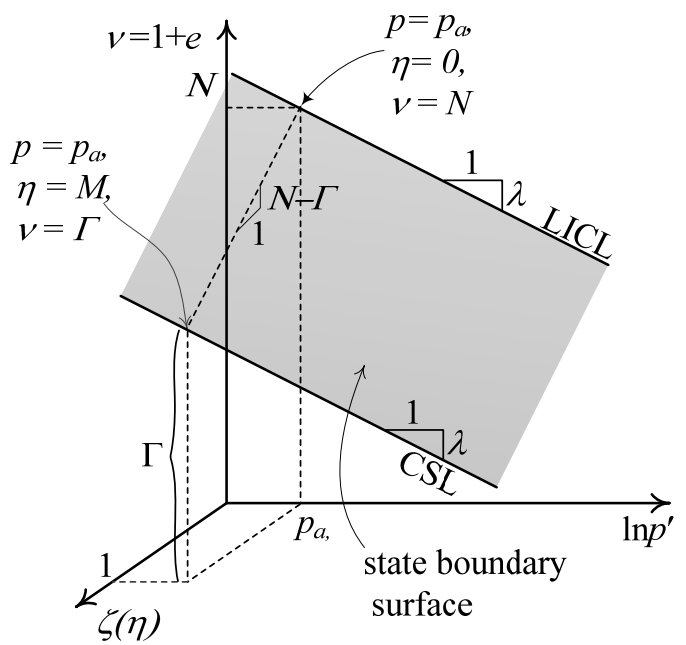

Figure 6: Specific volume of destructured soft rocks in the least dense state.

The healing and decay of the rock structure could be incorporated by extending the

critical state concept. In this study, the kernel concept assumed that the rock structure was newly introduced to represent the upward shift of the state boundary surface due to structure in the $p^{\prime}-\zeta(\eta)-v$ space as indicated in Figure 7. From this, the state parameter $\Psi$ was a non-negative variable defined as the volumetric distance between the state boundary surfaces for non-structured and structured states. The specific volume on the state boundary surface of structured soft rock, $v_{\text {sbs }}^{\text {structure }}$, could thus be described in a similar way to 207 Equation (6):

$$
v_{\text {sbs }}^{\text {structure }}=N-\lambda \ln \frac{p^{\prime}}{p_{\mathrm{a}}}+(\Gamma-N) \zeta(\eta)+\Psi \#(8)
$$

The upper limit of $v_{\mathrm{sbs}}^{\text {structure }}$ under the current state $\left(p^{\prime}, \eta, \Psi\right)$ varies with structure, and a higher mean effective stress can be applied to soft rock having a higher value of the state variable $\Psi$ for the structures, without yielding. Besides, the structures may also impart cohesion and tensile strength to the soft rock, which can be modeled by the expansion of the yield surface toward the negative direction of mean effective stress. Such an effect can be 
213 incorporated in a similar way as in the existing models for soft rocks, based on the critical 214 state theory $[11,13,14]$.

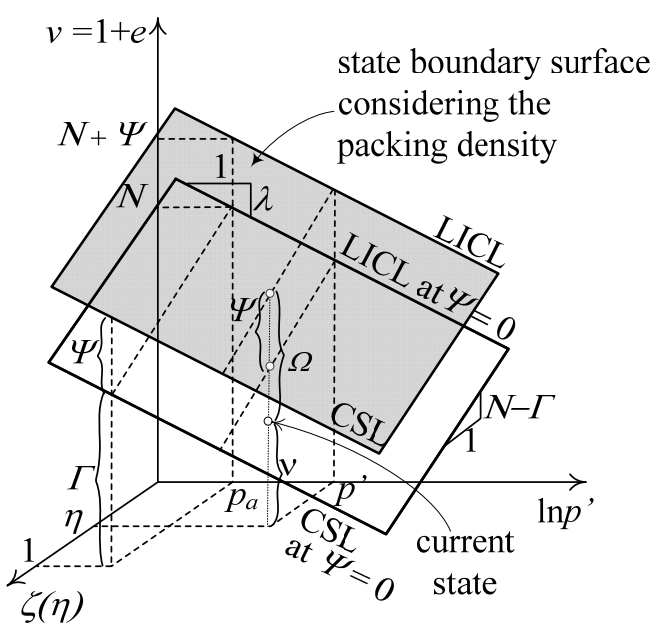

Figure 7: Specific volume of structured soft rocks in the least dense state via state parameter

downward movement of the state boundary surface in the volumetric plane of $\ln p^{\prime}$ and $v$, surface (in the $v$-ln $p^{\prime}$ plane) shifted upward in the direction of the specific volume to increase 224 the upper limit of the specific volume. Assuming a deformation-dependent damage mechanism and time-dependent healing mechanism of the rock structure, the evolution of $\Psi$ can be given as

$$
\frac{\dot{\Psi}}{v_{0}}=\underbrace{-S^{d}(\Psi)\left\|\dot{\varepsilon}^{p}\right\|}_{\text {decay }}+\underbrace{S^{h}(\Psi)}_{\text {healing }} \#(9)
$$

227 where $S^{d}(\Psi)$ and $S^{h}(\Psi)$ are functions of $\Psi$. The first term of Eq. (9) describes the plastic 228 strain-driven decay of the structure. As the state parameter $\Psi$ decreases to zero with the 229 plastic strain development, $S^{d}(\Psi)>0$ when $\Psi>0$, and $S^{d}(0)=0$. An evolution that satisfies such requirements is given by 


$$
S^{d}(\Psi)=b \Psi^{2} \#(10)
$$

231 where $b$ is a constitutive parameter controlling the rate of decay of the structure. The second 232 term of Eq. (9) describes the time-dependent healing of the structure, and $S^{h}(\Psi)$ is a function 233 of $\Psi$ representing the healing rate of the rock structure. Though this function may be 234 dependent on the confining pressure and other factors, a simplified expression of the healing 235 rate is given in this study as

$$
S^{h}(\Psi)=\frac{1}{v_{0}} \frac{\Psi_{\mathrm{max}}-\Psi}{t_{\mathrm{ref}}} \#(11)
$$

236 as shown in Figure 8 (a), where $\Psi_{\max }$ is a parameter defining the maximum value of $\Psi$, and $237 t_{\text {ref }}$ is a parameter having a dimension of time, which describes the convergence rate of $\Psi$ to $\Psi_{\text {max }}$. We could explicitly describe the variation of the state parameter $\Psi$ due to timedependent healing by integrating Eq. (9) if we assumed that initially the rock had no structure $(t=0, \Psi=0)$ and that no plastic deformation occurs $\left(\dot{\varepsilon}^{p}=0\right)$

$$
\Psi=\Psi_{\max }\left(1-\exp \frac{t}{t_{\mathrm{ref}}}\right)
$$

241 From this equation, $\Psi$ increases with time until it approaches its maximum value $\Psi_{\max }$, as 242 shown in Figure 8 (b).
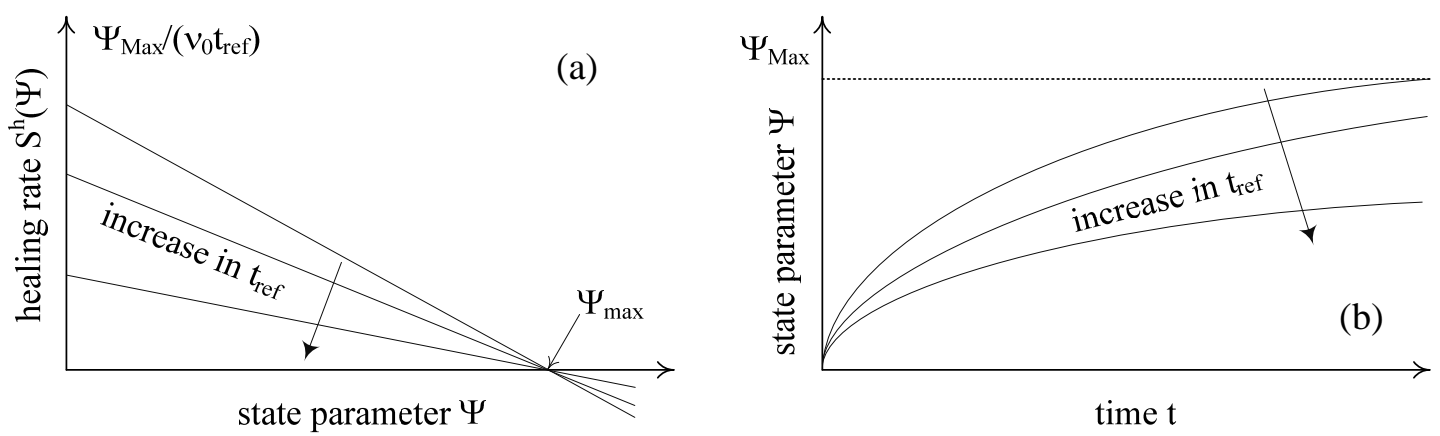

Figure 8: Modeling of the time-dependent healing of the rock structure via state parameter 
The subloading surface concept [16] was further introduced to describe the

249

250

251

252

253

254

255

256

257

258

259

260

261

262

263

264

where $\omega$ is a parameter controlling the effect of density.

$$
\frac{\dot{\Omega}}{v_{0}}=-Q(\Omega)\left\|\dot{\varepsilon}^{\mathrm{p}}\right\| \#(14)
$$

$$
Q(\Omega)=\omega \Omega^{2} \#(15)
$$

$$
v=v_{\text {sbs }}^{\text {structure }}-\Omega=N-\lambda \ln \frac{p^{\prime}}{p_{\mathrm{a}}}+(\Gamma-N) \zeta(\eta)+\Psi-\Omega . \#(13)
$$

State parameter $\Omega$ always refers to the volumetric distance from the current state to the least dense state of soft rock (specific volume on the state boundary surface) under the current stress condition $p^{\prime}$ and $q$ as well as the current state parameter $\Psi$ for the rock structure.

During plastic flow, $\Omega$ decreased with the development of plastic deformation and converged to zero. The evolution of $\Omega$ could therefore be represented by

where $\dot{\varepsilon}^{p}$ is the plastic strain rate tensor and $Q(\Omega)$ is a function of $\Omega$ given by 

Eq. (13) as

$$
\text { change. }
$$

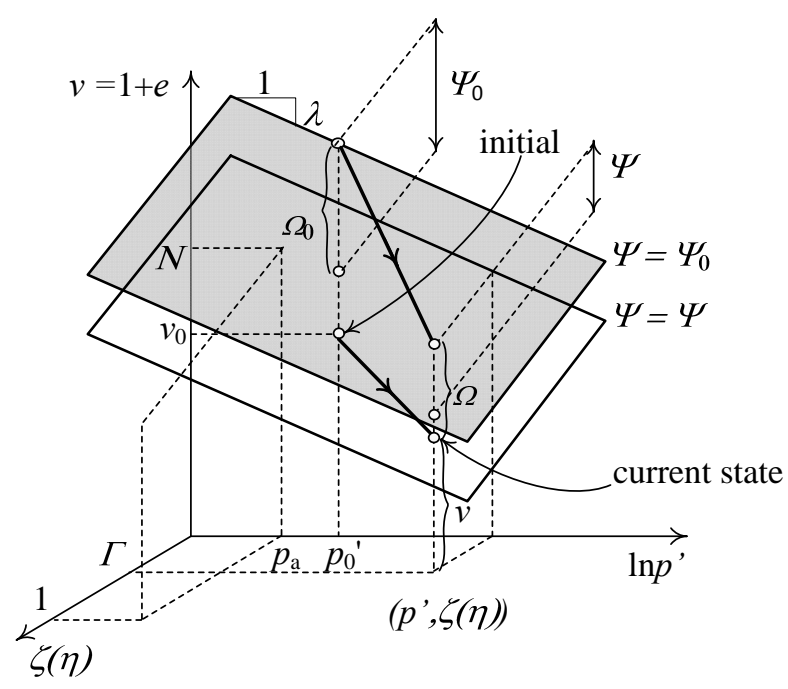

Figure 9: Modeling of the volumetric behavior of soft rocks considering the structural From the current specific volume $v$ (Eq. (13)), the initial specific volume $v_{0}$ can be obtained by substituting the initial states $v=v_{0}, \Psi=\Psi_{0}, \Omega=\Omega_{0}, p^{\prime}=p_{0}^{\prime}$, and $q=0$ in

$$
v_{0}=N-\lambda \ln \frac{p_{0}}{p_{\mathrm{a}}}+\Psi_{0}-\Omega_{0} . \#(16)
$$

274 The total volumetric strain (where compression is assumed to be positive) generated from the 275 initial state to the current state is given by

$$
\varepsilon_{\mathrm{v}}=-\frac{\mathrm{d} v}{v_{0}}=\frac{v_{0}-v}{v_{0}}
$$

276 By substituting Eqs. (13) and (16) in Eq. (17), we obtained

$$
\varepsilon_{\mathrm{v}}=\frac{1}{v_{0}}\left\{\lambda \ln \frac{p^{\prime}}{p_{0}^{\prime}}+(N-\Gamma) \zeta(\eta)-\left(\Psi-\Psi_{0}\right)+\left(\Omega-\Omega_{0}\right)\right\} \#(
$$

277 by taking the trace on both sides of Eq. (3), the elastic volumetric strain could be obtained:

$$
\varepsilon_{\mathrm{v}}^{\mathrm{e}}=\frac{\kappa}{v_{0}} \ln \frac{p^{\prime}}{p_{0}^{\prime}} \#(19)
$$

278 The plastic volumetric strain could be determined by taking the difference between the total 
volumetric strain given by Eq. (18) and the elastic volumetric strain given by Eq. (19):

$$
\varepsilon_{\mathrm{v}}^{\mathrm{p}}=\frac{1}{v_{0}}\left\{(\lambda-\kappa) \ln \frac{p^{\prime}}{p_{0}^{\prime}}+(N-\Gamma) \zeta(\eta)-\left(\Psi-\Psi_{0}\right)+\left(\Omega-\Omega_{0}\right)\right\} \#(20)
$$

280 From Eq. (20), the yield function $f$ for soft rocks, which considered the effect of the structure,

could be written as follows:

$$
f=\frac{1}{v_{0}}\left\{(\lambda-\kappa) \ln \frac{p^{\prime}}{p_{0}^{\prime}}+(N-\Gamma) \zeta(\eta)-\left(\Psi-\Psi_{0}\right)+\left(\Omega-\Omega_{0}\right)\right\}-\varepsilon_{\mathrm{v}}^{\mathrm{p}} \#(21)
$$

Assuming associated flow in the proposed model, we obtained the plastic strain rate tensor:

$$
\dot{\varepsilon}^{\mathrm{p}}=\langle\dot{\Lambda}\rangle \frac{\partial f}{\partial \boldsymbol{\sigma}^{\prime}} \#(22)
$$

where $\dot{\Lambda}$ is the rate of the plastic multiplier. The loading criterion was thus given by $\dot{\Lambda}>0$.

Since an unlimited distortional strain was exhibited at the critical state without any change in follows:

$$
f=\frac{\lambda-\kappa}{v_{0}}\left[\ln \frac{p^{\prime}}{p_{0}^{\prime}}+\ln \left\{1+\left(\frac{\eta}{M}\right)^{2}\right\}\right]-\frac{\Psi-\Psi_{0}}{v_{0}}+\frac{\Omega-\Omega_{0}}{v_{0}}-\varepsilon_{\mathrm{v}}^{\mathrm{p}_{2}} \#(23)
$$

\subsection{Elastoplastic stress-strain relationship}

289

290

291

292

293

In the purely elastic regime, the rate of the plastic multiplier $\langle\dot{\Lambda}\rangle$ remains zero. Meanwhile, during elastoplastic deformation, the stress remains on the yield surface, and the yield function $f$ remains equal to zero. The time derivative of the yield function $\dot{f}$ consequently vanishes whenever the rate of the plastic multiplier $\langle\dot{\Lambda}\rangle$ is positive. Therefore, we could write a consistency condition that has validity for either elastic or elastoplastic deformation as

$$
0=\langle\dot{\Lambda}\rangle \dot{f}
$$

During plastic flow, we applied the consistency condition to the time derivative of the yield function $\dot{f}\left(\boldsymbol{\sigma}^{\prime}, \varepsilon_{\mathrm{v}}^{\mathrm{p}}, \Psi, \Omega\right)$ calculated from Eq. (23) as follows 


$$
\begin{gathered}
\dot{f}=\frac{\partial f}{\partial \boldsymbol{\sigma}^{\prime}}: \dot{\boldsymbol{\sigma}}^{\prime}+\frac{\partial f}{\partial \Psi} \dot{\Psi}+\frac{\partial f}{\partial \Omega} \dot{\Omega}+\frac{\partial f}{\partial \varepsilon_{v}^{p}} \dot{\varepsilon}_{v}^{p} \#(25) \\
\dot{f}=\frac{\lambda-\kappa}{v_{0}}\left[\frac{1}{p^{\prime}} \frac{\partial p^{\prime}}{\partial \boldsymbol{\sigma}^{\prime}}+\frac{2 \eta}{M^{2}+\eta^{2}} \frac{\partial \eta}{\partial \boldsymbol{\sigma}^{\prime}}\right]: \dot{\boldsymbol{\sigma}}^{\prime}-\frac{\dot{\Psi}}{v_{0}}+\frac{\dot{\Omega}}{v_{0}}-\dot{\varepsilon}_{\mathrm{v}}^{\mathrm{p}}=0 \#(26)
\end{gathered}
$$

296 Substituting Eqs. (3), (9), (14), (15), and (22) in Eq. (26), we obtained the plastic multiplier:

$$
\langle\dot{\Lambda}\rangle=\left\langle\frac{\frac{\partial f}{\partial \boldsymbol{\sigma}^{\prime}}: \boldsymbol{D}^{e}: \dot{\boldsymbol{\varepsilon}}-S^{h}(\Psi)}{\operatorname{tr}\left(\frac{\partial f}{\partial \boldsymbol{\sigma}^{\prime}}\right)+\frac{\partial f}{\partial \boldsymbol{\sigma}^{\prime}}: \boldsymbol{D}^{e}: \frac{\partial f}{\partial \boldsymbol{\sigma}^{\prime}}+\left\{Q(\Omega)-S^{d}(\Psi)\right\}\left\|\frac{\partial f}{\partial \boldsymbol{\sigma}^{\prime}}\right\|}\right\rangle . \#(27)
$$

297 We consequently obtained the rate form of the elastoplastic stress-strain relationship from 298 Eqs. (3), (21), and (26):

$$
\dot{\boldsymbol{\sigma}}^{\prime}=\boldsymbol{D}^{\mathrm{e}}: \dot{\boldsymbol{\varepsilon}}-\left\langle\frac{\frac{\partial f}{\partial \boldsymbol{\sigma}^{\prime}}: \boldsymbol{D}^{e}: \dot{\boldsymbol{\varepsilon}}-S^{h}(\Psi)}{\operatorname{tr}\left(\frac{\partial f}{\partial \boldsymbol{\sigma}^{\prime}}\right)+\frac{\partial f}{\partial \boldsymbol{\sigma}^{\prime}}: \boldsymbol{D}^{e}: \frac{\partial f}{\partial \boldsymbol{\sigma}^{\prime}}+\left\{Q(\Omega)-S^{d}(\Psi)\right\}\left\|\frac{\partial f}{\partial \boldsymbol{\sigma}^{\prime}}\right\|}\right\rangle \boldsymbol{D}^{\mathrm{e}}: \frac{\partial f}{\partial \boldsymbol{\sigma}^{\prime}} \#(28)
$$

299 When the rate of the plastic multiplier $\Lambda$ is positive, the rate form of the elastoplastic stress300 strain relationship can be expressed as

$$
\dot{\sigma}^{\prime}=D^{e p}: \dot{\varepsilon}-D^{t} \#(29)
$$

where $\boldsymbol{D}^{e p}$ and $\boldsymbol{D}^{t}$ are defined as follows:

$$
\begin{gathered}
\boldsymbol{D}^{e p}=\boldsymbol{D}^{e}-\frac{\boldsymbol{D}^{e}: \frac{\partial f}{\partial \boldsymbol{\sigma}^{\prime}} \otimes \frac{\partial f}{\partial \boldsymbol{\sigma}^{\prime}}: \boldsymbol{D}^{e}}{\operatorname{tr}\left(\frac{\partial f}{\partial \boldsymbol{\sigma}^{\prime}}\right)+\frac{\partial f}{\partial \boldsymbol{\sigma}^{\prime}}: \boldsymbol{D}^{e}: \frac{\partial f}{\partial \boldsymbol{\sigma}^{\prime}}+\left\{Q(\Omega)-S^{d}(\Psi)\right\}\left\|\frac{\partial f}{\partial \boldsymbol{\sigma}^{\prime}}\right\|} \|^{\boldsymbol{D}^{e}: \frac{\partial f}{\partial \boldsymbol{\sigma}^{\prime}} S^{h}(\Psi)} \\
\boldsymbol{D}^{t}=\frac{\operatorname{tr}\left(\frac{\partial f}{\partial \boldsymbol{\sigma}^{\prime}}\right)+\frac{\partial f}{\partial \boldsymbol{\sigma}^{\prime}}: \boldsymbol{D}^{e}: \frac{\partial f}{\partial \boldsymbol{\sigma}^{\prime}}+\left\{Q(\Omega)-S^{d}(\Psi)\right\}\left\|\frac{\partial f}{\partial \boldsymbol{\sigma}^{\prime}}\right\|}{\#(31)}
\end{gathered}
$$

\subsection{Determination of the parameters involved in the proposed model.}

The first set of constitutive parameters $(\lambda, \kappa, N, M, v, \mathrm{a})$ can be readily obtained from the 
306

307

308

309

310

311

312

swelling line unloading part, and $N$ from the specific volume on the LICL under atmospheric pressure at the destructured state. The parameter " $a$ " can be obtained by fitting the compression curve under the reloading path. The slope $M$ of the CSL in the $q-p^{\prime}$ plane, and Poisson's ratio $v$, are then calibrated from the result of the monotonic triaxial CD or $\overline{\mathrm{CU}}$ tests. The second set of constitutive parameters $\left(b, t_{r e f}, \Psi_{0}, \Psi_{\max }\right)$ that control the rate of the decay and healing of the rock structure can be deduced by fitting the simulations to SHS triaxial tests. $\Psi_{0}$ and $\Psi_{\max }$ are the initial "structure" and the maximum "structure" assumed in the material, respectively. Their values can be obtained by fitting the stress-strain relationship for the SHS tests, so that the material can gain its maximum structure. $1 / t_{\text {ref }}$ describes the rate of the increase in $\Psi$ to $\Psi_{\max }$ when the rock gains its structrure during the hold phase. " $b$ " describes the rate of decrease in $\Psi$ under plastic deformation.

\section{Simulation results}

\subsection{Monotonic triaxial shearing and decay of the structure}

The proposed model was compared with the monotonic triaxial shearing test under drained conditions with a constant effective confining pressure (Adachi and Oka [13]) to validate the modeling of structural decay due to deformation. The set of material parameters shown in Table 1 was used for all simulations with different confining pressures. The initial conditions are summarized in Table 2. The axial strain rate applied during the drained triaxial shearing was $3.33 \% / \mathrm{h}$. As shown in Figure 10, the proposed model can capture the tendency of strain hardening and strain softening as well as the tendency of dilatancy in soft rock.

Table 1: Constitutive parameters for soft rock (pumice lapilli tuff) for the monotonic triaxial CD test.

\begin{tabular}{llc}
\hline$\lambda$ & Compression index & 0.053 \\
\hline $\boldsymbol{\kappa}$ & Swelling index & 0.004 \\
\hline
\end{tabular}




\begin{tabular}{clc}
\hline $\boldsymbol{M}$ & Critical state stress ratio & 1.7 \\
\hline $\boldsymbol{N}$ & Void ratio on LICL at atmospheric pressure $p^{\prime}(=98$ & 0.83 \\
& $\mathrm{kPa})$ & 0.12 \\
\hline $\boldsymbol{v}$ & Poisson's ratio & $1 \times 10^{4}$ \\
\hline $\boldsymbol{\omega}$ & Rate of evolution of $\Omega$ & 100 \\
\hline $\boldsymbol{b}$ & Rate of decay of rock structure $\Psi$ due to plastic strain & 0.10 \\
\hline $\mathbf{1} / \mathbf{t}_{\mathbf{r e f}}$ & Rate of healing of rock structure $\Psi[1 / \mathrm{h}]$ & 0.90 \\
\hline $\boldsymbol{\Psi}_{\mathbf{m a x}}$ & Upper limit of rock structure $\Psi$ & \\
&
\end{tabular}
pressures.

\begin{tabular}{ccc}
\hline $\begin{array}{c}\text { Effective confining } \\
\text { stress } \boldsymbol{\sigma}_{\mathbf{0}}^{\prime} \mathbf{( k P a )}\end{array}$ & $\begin{array}{c}\text { Initial void } \\
\text { ratio } \boldsymbol{e}_{\mathbf{0}}\end{array}$ & $\begin{array}{c}\text { Initial state } \\
\text { parameter } \boldsymbol{\Psi}_{\mathbf{0}}\end{array}$ \\
\hline 98 & 0.72 & 0.105 \\
\hline 490 & 0.72 & 0.130 \\
\hline 980 & 0.72 & 0.125 \\
\hline 1960 & 0.72 & 0.130 \\
\hline
\end{tabular}

332
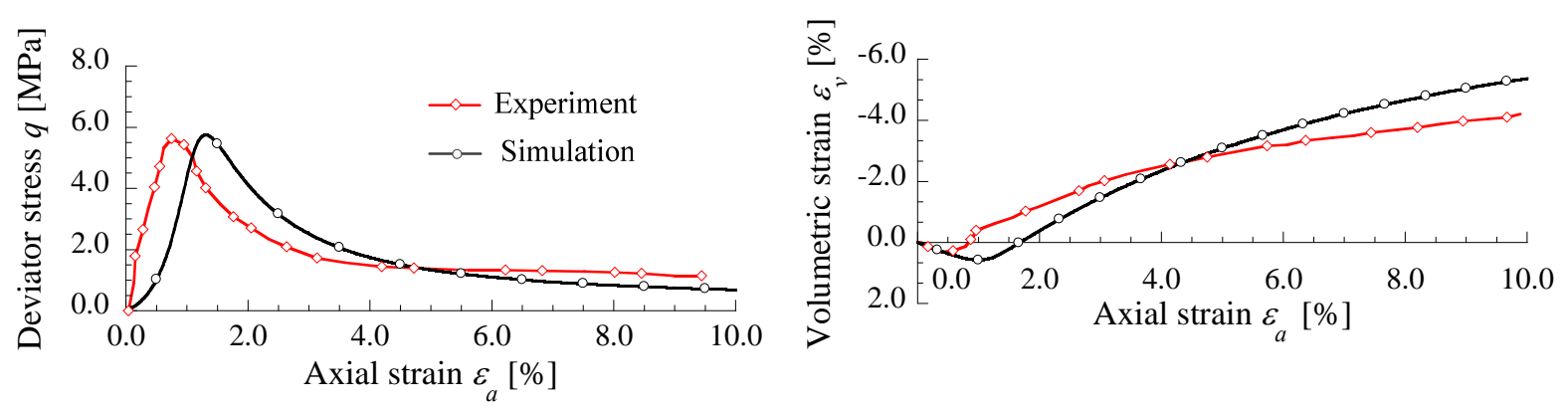

(a) Effective confining pressure $\sigma_{r}=98 \mathrm{kPa}$ 

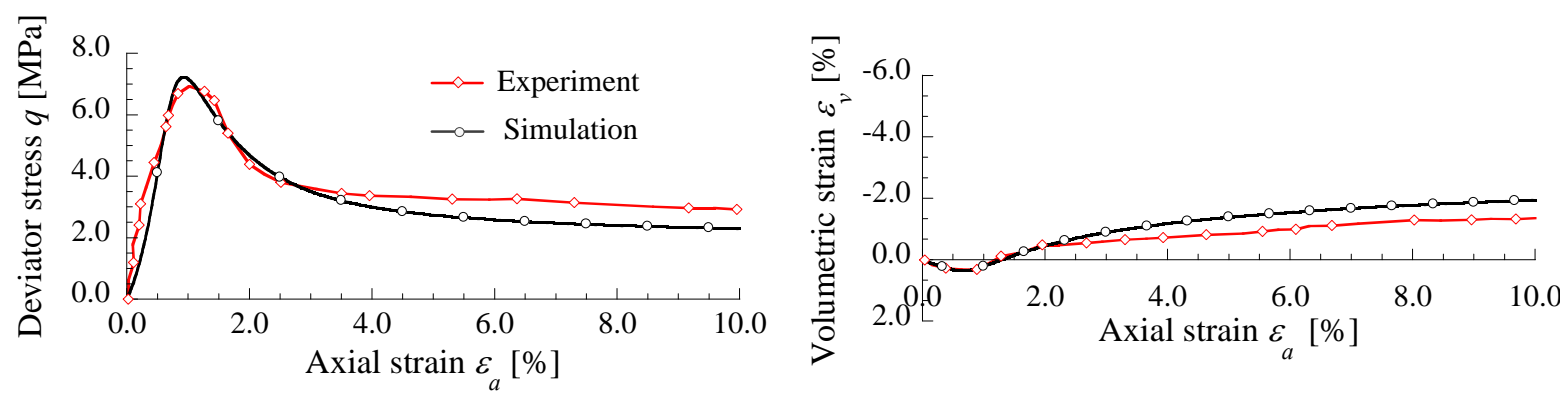

(b) Effective confining pressure $\sigma_{r}=490 \mathrm{kPa}$
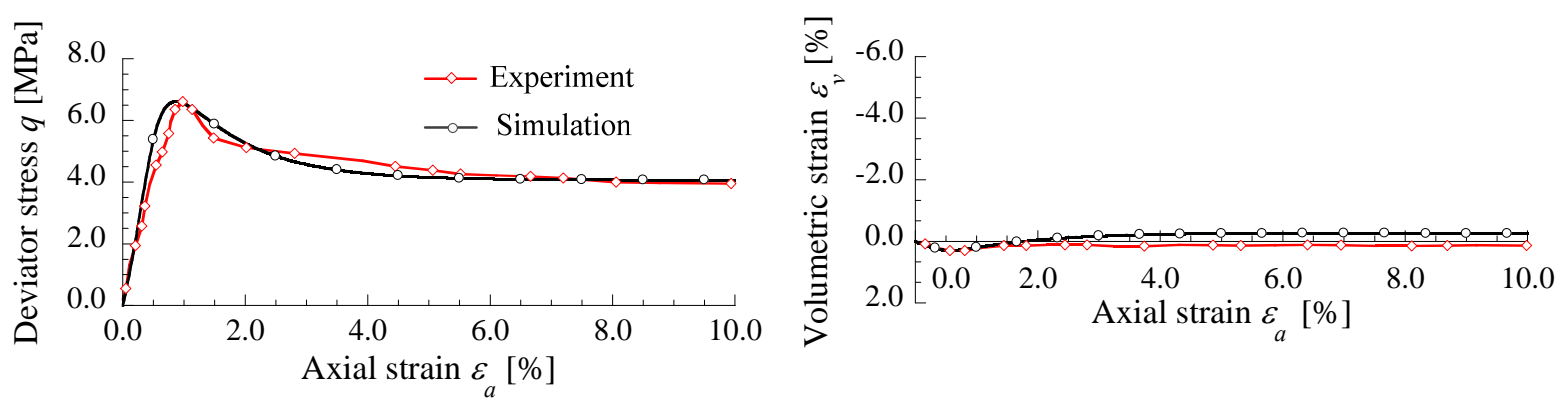

337

(c) Effective confining pressure $\sigma_{r}=980 \mathrm{kPa}$

339
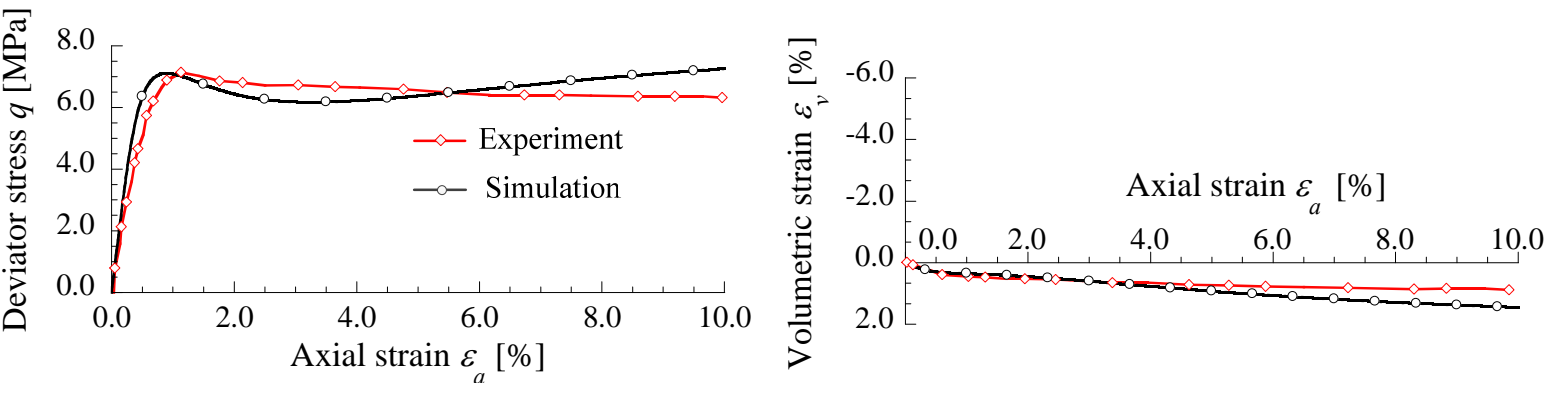

(d) Effective confining pressure $\sigma_{r}=1960 \mathrm{kPa}$

Figure 10: Comparison between experimental and numerical simulation results on

consolidated, drained monotonic triaxial compression test for various confining pressures.

\subsection{Slide-hold-slide triaxial shearing and structural healing and decay}

The characteristics of the proposed model are explained using examples of the simulation results of the SHS triaxial test shown in Figure 11 and Figure 12. SHS shearing was simulated under the drained condition with a constant effective confining pressure of 700 $\mathrm{kPa}$. Four holding processes were applied with a stepwise increase in the holding time periods. 
In the model, the state parameter $\Psi$ increased due to the effect of the holding time

351 (Figure 11 (c) and Figure 12 (c)) in the evolution law in Eq. (9). The increase in $\Psi$ led to the 352 upward movement of the state boundary surface in the plane of mean effective stress and 353 specific volume. Consequently, the state parameter $\Omega$, which is the specific volume difference 354 between the current state and the least dense state under the same state on the state boundary 355 surface, also increased (Figure 11 (d) and Figure 12 (d)). As the holding time increased, $356 \Psi$ increased. After a certain long holding time, $\Psi$ gradually reached its maximum value $\Psi_{\max }$, 357 which was assumed as the fully structured state of the rock. Decay in the rock strength was observed in the re-sliding process. First, $\Psi$ decreased (Figure 11 (c)) because of the larger decay effect of plastic strain over the healing effect of holding time in the evolution of the state variable in Eq. (9). The decrease in $\Psi$ moved the state boundary surface downward in

361 the direction of specific volume, leading to a decrease in the state variable $\Omega$ (Figure 11 (d)). This resulted in a decrease in the stiffness. In addition, the deviator stress increased with a rather high stiffness, reaching a peak value before returning to the residual value. The magnitude of the strength recovery depended on the duration of the holding process, as higher peak strengths were typically observed after a longer holding time. 

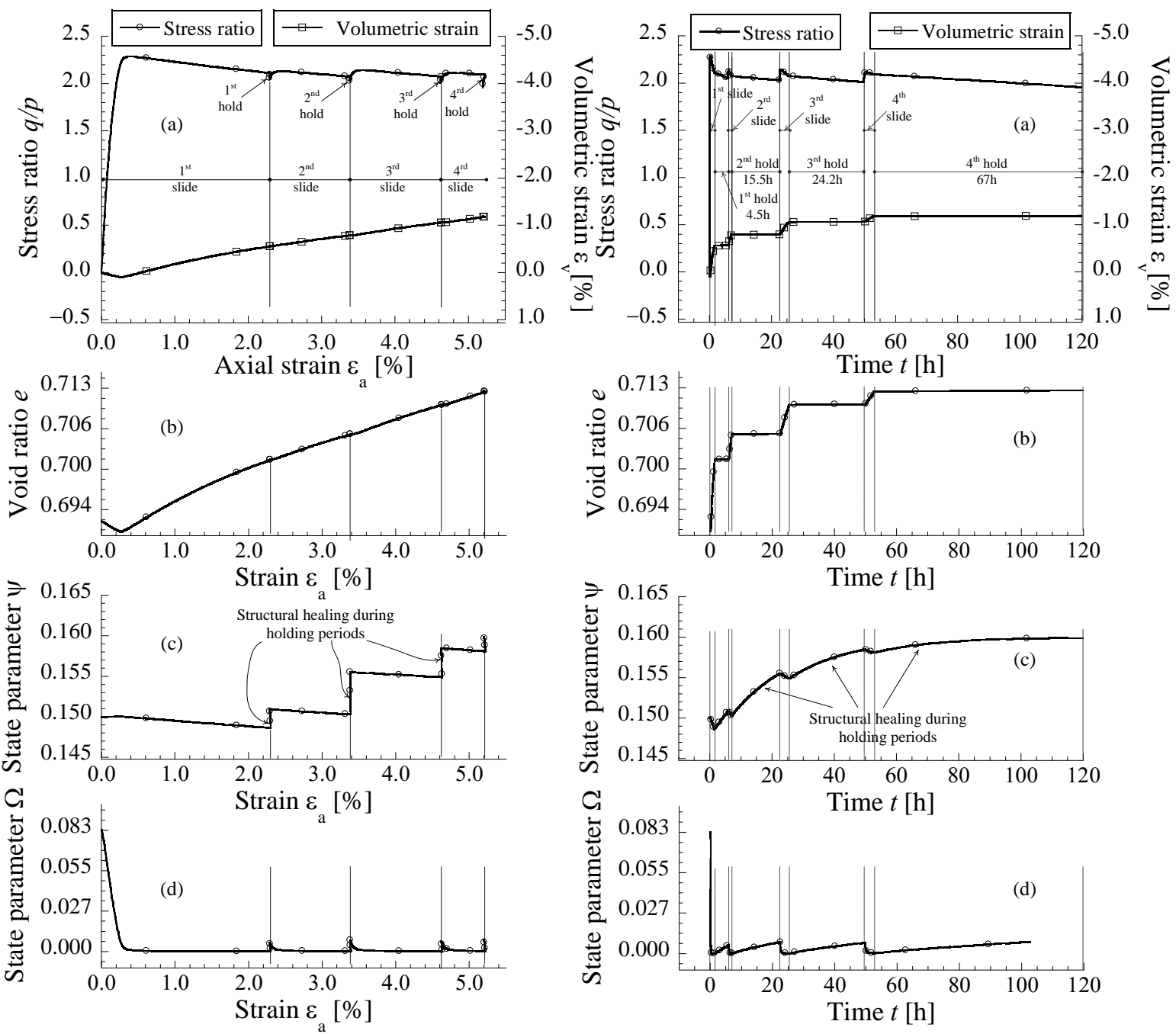

SHS triaxial CD test

(variations in relation to time) processes under constant effective confining pressures of 300 and $700 \mathrm{kPa}$ were simulated using the proposed model. The constitutive parameters used for the simulation are listed in Table 3, while the initial conditions are given in Table 4.

From Figures 13, 14, 15, and 16, the proposed model accurately predicted the stress-

377 time-strain relationship of soft rock with SHS processes under two different effective confining pressures. The healing and decay phenomena of the soft rock structure and their effect on the strength and dilatancy characteristics were properly captured by the proposed 
380 model. The characteristic of the proposed model was confirmed: longer holding times result

381 in greater recovery of the rock strength.

382

Table 3: Constitutive parameters for soft rock (pumice lapilli tuff) for the SHS triaxial CD

test

\begin{tabular}{clc}
\hline $\boldsymbol{\lambda}$ & Compression index & 0.0360 \\
\hline $\boldsymbol{\kappa}$ & Swelling index & 0.0012 \\
\hline $\boldsymbol{M}$ & Critical state stress ratio & 1.9 \\
\hline $\boldsymbol{N}$ & Void ratio on LICL at atmospheric pressure $p^{\prime}(=98$ & 0.70 \\
& $\mathrm{kPa})$ & \\
\hline $\boldsymbol{v}$ & Poisson's ratio & 0.30 \\
\hline $\boldsymbol{\omega}$ & Rate of evolution of $\Omega$ & $3 \times 10^{5}$ \\
\hline $\boldsymbol{b}$ & Rate of decay of $\Psi$ due to plastic strain & 2.0 \\
\hline $\mathbf{1} / \mathbf{t}_{\mathbf{r e f}}$ & Rate of healing of rock structure $\Psi[1 / \mathrm{h}]$ & 0.05 \\
\hline $\boldsymbol{\Psi}_{\mathbf{m a x}}$ & Upper limit of rock structure $\Psi$ & 0.16
\end{tabular}

385

Table 4: Initial conditions for the SHS triaxial CD test

\begin{tabular}{ccc}
\hline Effective confining stress & Initial void & Initial state \\
$\boldsymbol{\sigma}_{\mathbf{0}}^{\prime}(\mathbf{k P a})$ & ratio $\boldsymbol{e}_{\mathbf{0}}$ & parameter $\boldsymbol{\Psi}_{\mathbf{0}}$ \\
\hline 300 & 0.692 & 0.15 \\
\hline 700 & 0.692 & 0.15
\end{tabular}


389

390

391

392

393

394

395

396
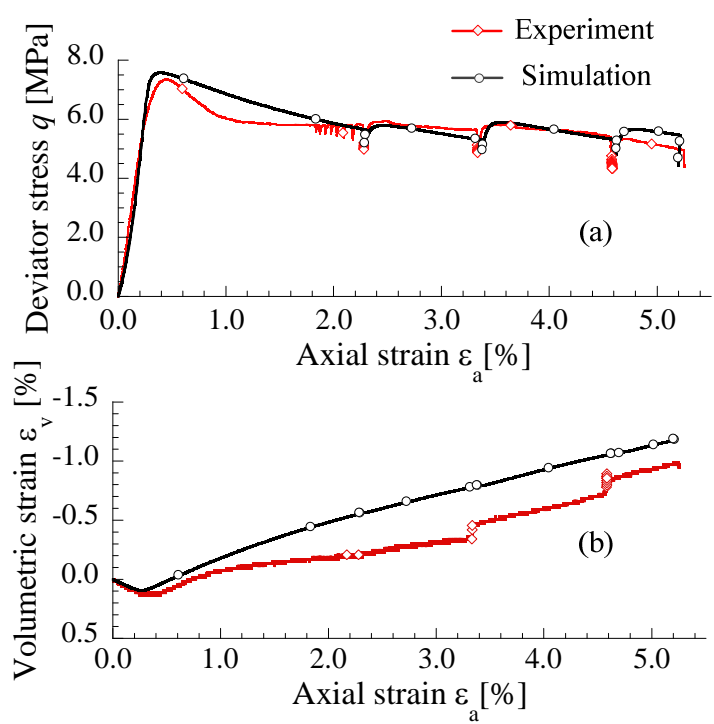

397

398

399

400

401

402

Figure 13: Comparison of the experimental
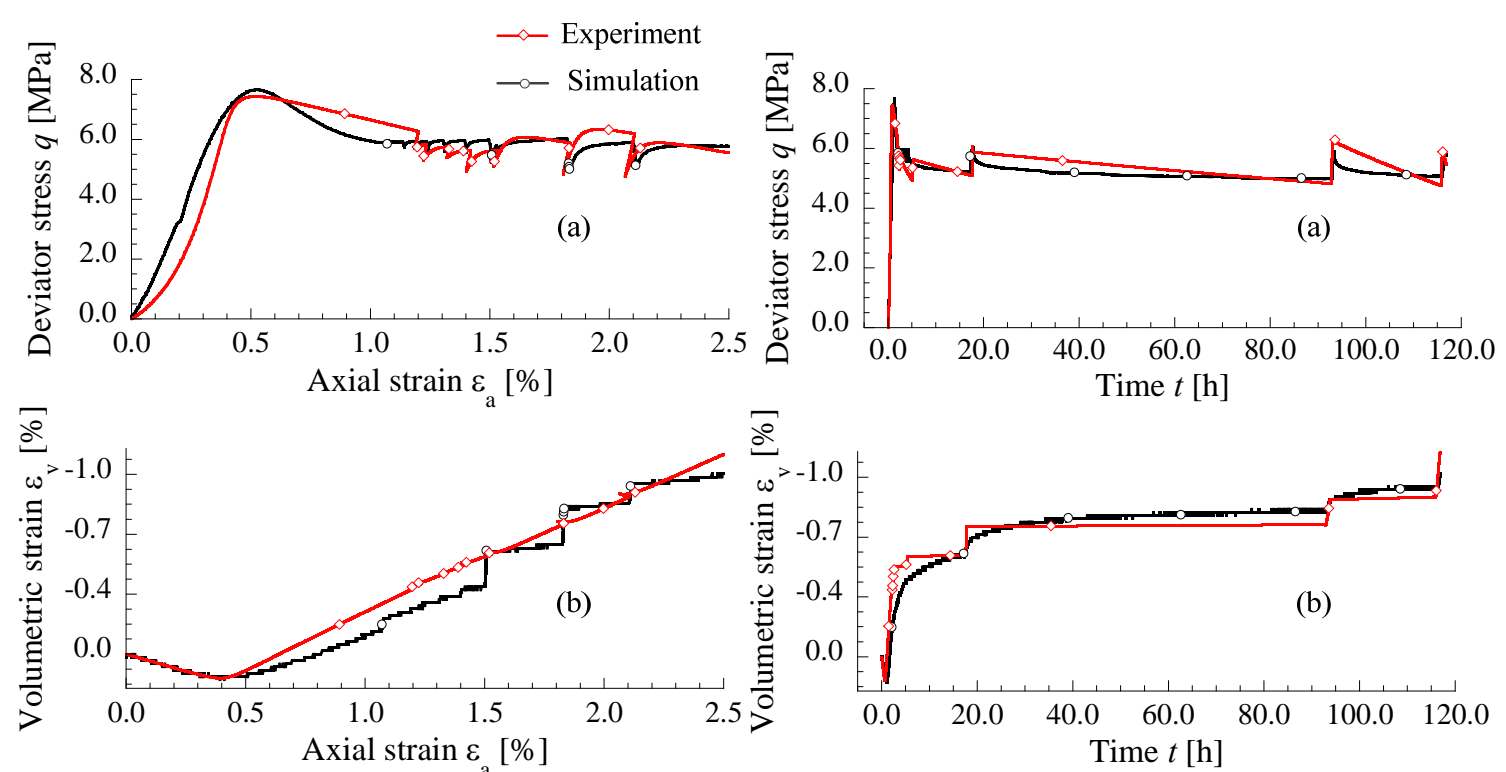

Figure 14: Comparison of the experimental and numerical simulation results of the SHS triaxial CD test $\sigma_{r}=300 \mathrm{kPa}$ (variation in relation with time)
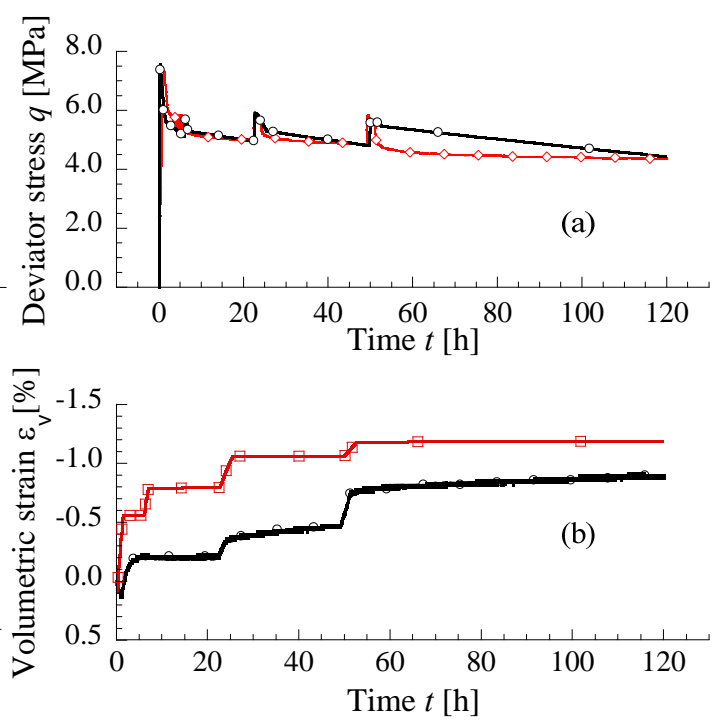

Figure 16: Comparison of the experimental and numerical simulation results of the SHS triaxial CD test $\sigma_{r}=700 \mathrm{kPa}$ (variation in relation with time) 
403

404

405

406

407

408

409

410

411

412

413

414

415

416

417

418

419

420

421

422

423

424

425

426

427

\subsection{Parametric study via monotonic shear in consolidated, drained triaxial compression} test

A parametric study of the proposed model was presented using numerical simulations of a monotonic triaxial compression test in the consolidated, drained condition. The same material parameters and initial conditions as those listed in Table 3 and Table 4 were applied in this simulation. Analysis was performed on the effect of material parameter $b$ accounting for the decaying rate with different values of $b$ ranging from 2 to 16 and the effects of a wide range of strain rates (from $2.5 \times 10^{-3} \% / \mathrm{h}$ to $8.0 \times 10^{-2} \% / \mathrm{h}$ ).

Figure 17 shows that different decaying rates of rock friction for different rock types can be controlled by the material parameter $b$ in the proposed model. As the value of $b$ or the strain rate increases, both decaying of rock friction and a lower negative dilatancy during the softening process were observed. Similarly, different healing rates for various rock types can also be controlled through the material parameters $t_{\text {ref. }}$ Meanwhile, as shown in Figure 18, the proposed model can consider the effect of different shearing rates on the behavior of the same rock. These parameters should be determined by analyzing the experimental results of SHS tests for each type of rock.

Regarding the strength, as observed in Figure 17 (a), the rock reached its critical state stress ratio, in which $(q / p)_{\mathrm{cs}}=M$. The rate of structural decay could be studied by observing the variation of the state variable $\Psi$ in Figure 17 (c) and 18 (c) when either $b$ or the strain rate was changed. In Figure 18 (c), $\Psi$ reaches a limiting value, in which $d \Psi$ is zero. In this limiting state, the healing and decay given by Eq. (9) likely had the same amount of effect on the rock friction. The state variable $\Omega$, which is the distance from the current void ratio to the ratio on the state boundary surface at the same mean stress, started from an initial value and gradually converged to zero. 

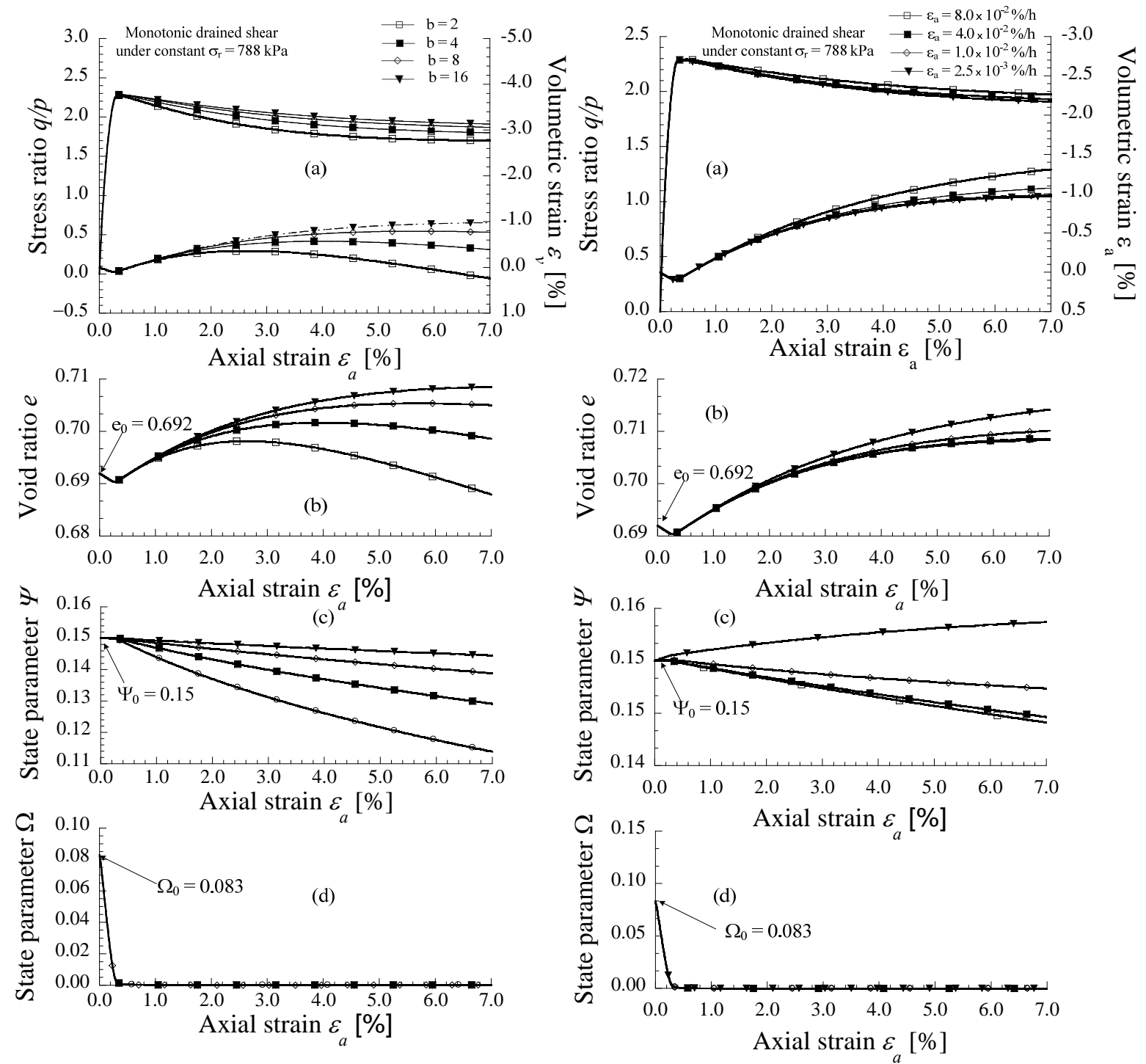

Figure 1: Simulation results of the effect

Figure 2: Simulation results of the effect

of parameter $b$ on the decay rate

in monotonic triaxial shear test under

the consolidated drained condition.

of the strain rate on the decay rate

in monotonic triaxial shear test under

the consolidated drained condition.

\section{Conclusion}

435 In summary, this study has highlighted the effects of structural healing and decay on the stress-strain characteristics of soft rock and presented a potential approach for describing the

437 healing and decay of a rock structure in the formulation of an elastoplastic constitutive model. The model performance was validated by comparing simulations with the experimental results of drained, monotonic triaxial shearing tests and drained SHS triaxial shearing tests on soft sedimentary rock. Unlike the existing models for structured soil and 
441

442

443

444

445

446

447

448

449

450

451

452

453

454

455

456

457

458

459

460

461

462

463

soft rock, our model is capable of describing the time-healing effect of the structure as well as the decay of the structure due to deformation. Our constitutive model is formulated based on a general stress-strain tensor. Thus, it is easy to implement the model in a finite element method to analyse any geotechnical problems considering the long-term behavior of soft sedimentary rocks.

\section{Acknowledgments}

Funding: This work was supported by JSPS KAKENHI [grant numbers 26249139, 15K14030]. The second author was financially supported by the Monbukagakusho (MEXT) scholarship. We thank Mr. Takenori Araki and Mr. Masato Ohno, formerly graduate students at Kyoto University, for their support in conducting the experiments.

\section{Appendix}

The following notations and symbols are used in the present paper: bold letters denote vectors and matrices; the symbol “.” denotes an inner product of two vectors (e.g., $\mathbf{a} \cdot \mathbf{b}=$ $\left.a_{\mathrm{i}} b_{\mathrm{i}}\right)$ or a single contraction of the adjacent indices of two tensors (e.g., $\left.(\mathbf{c} \cdot \mathbf{d})_{\mathrm{ij}}=c_{\mathrm{ik}} d_{\mathrm{kj}}\right)$; the symbol “:” denotes an inner product of two second-order tensors (e.g., $\mathbf{c}: \mathbf{d}=c_{\mathrm{ij}} d_{\mathrm{ij}}$ ) or a double contraction of the adjacent indices of tensors of rank two and higher (e.g., (e: c $)_{\mathrm{ij}}=$ $\left.e_{\mathrm{ijkl}} c_{\mathrm{kl}}\right)$; “ $\bigotimes$ ” denotes a tensor product of two vectors (e.g., $\left.(\mathbf{a} \otimes \mathbf{b})_{\mathrm{ij}}=a_{\mathrm{i}} b_{\mathrm{j}}\right)$ or a tensor product of two second-order tensors (e.g., $\left.(\mathbf{c} \otimes \mathbf{d})_{\mathrm{ijkl}}=a_{\mathrm{ij}} b_{\mathrm{kl}}\right)$; “\| $\|$ ” denotes the norm of a vector (e.g., $\|\mathbf{a}\|=\sqrt{\mathbf{a} \cdot \mathbf{a}}=\sqrt{a_{\mathrm{i}} a_{\mathrm{i}}}$ ) or a second-order tensor (e.g., $\|\mathbf{c}\|=\sqrt{\mathbf{c}: \mathbf{c}}=\sqrt{c_{\mathrm{ij}} c_{\mathrm{ij}}}$ );

$\mathbf{1}$ is the second-order identity tensor; $\boldsymbol{I}$ is the fourth-order identity tensor $\left(I_{i j k l}=\right.$ $\left.\frac{1}{2}\left(\delta_{i k} \delta_{j l}+\delta_{i l} \delta_{j k}\right)\right)$; “〈 $\rangle$ ” is that Macaulay bracket that denotes the ramp function as $464<\mathrm{x}>=\left\{\begin{array}{l}\mathrm{x} \text { if } \mathrm{x}>0 \\ 0 \text { if } \mathrm{x} \leq 0\end{array}\right.$; over-dot “ ” " denotes the time derivative; and a zero subscript denotes 


\section{Reference}

[1] Shah DL, Shroff, AV. Rock structure and physical properties. In Soil mechanics and geotechnical engineering, CRC Press; 2003; Chapter 2: 6-21.

[2] Banks DC, Strohm WE, DeAugulo M, Lutton RJ. Study of clay-shale slopes along the Panama Canal. Report No. 3, Engineering analyses of slides and strength properties of clay shales along the Gaillard Cut. Technical report S-70-9. US Army Engineers Waterways Experiment station, Vickburg, Miss; 1975.

[3] Addis MA, Jones ME. Mechanical behavior and strain-rate dependence of high porosity chalk. In Proc Int Chalk Sympo, Brighton, London: Thomas Telford; 1990; 111-116.

[4] Aversa S, Evangelista A. The mechanical behaviour of a pyroclastic rock: yield strength and 'destructuration' effects. Rock Mech Rock Eng 1998; 31(1): 25-42.

[5] Aversa S, Evangelista A, Leroueil S, Picarelli L. Some aspects of the mechanical behaviour of 'structured' soils and soft rocks. In Proc Int Sym Geotechnics of Hard Soils - Soft Rocks, Athens: Balkema; 1993; 359-366.

[6] Pellegrino A. Mechanical behavior of soft rocks under high stresses. In Proc 2nd Int Congr Rock Mech, Belgrade; 1970; 2: 173-180.

[7] Leroueil S, Vaughan PR. The general and congruent effects of structure in natural soils and weak rocks. Géotechnique 1990; 40(3): 467-88.

[8] Kavvadas M. General report: Modelling the soil behaviour - Selection of soil parameters. In Proc Int Symp Geotechnics of Hard Soils-Soft Rocks, eds. Evangelista \& Picarelli, Naples: Balkema; 1998; 3: 1441-1481.

[9] Shao JF, Henry JP. Development of an elastoplastic model for porous rocks. Int J Plast 1991; 7(1-2): 1-13.

[10] Lade V. Elasto-plastic stress-strain theory for cohesionless soil with curved yield surfaces. Int J Solids Struct 1977; 13: 1019-35. 
493 [11] Gens A, Nova R. Conceptual bases for a constitutive model for bonded soils and weak $494 \quad$ rocks. In Proc Int Sym Geotechnics of Hard Soils - Soft Rocks, Athens: Balkema; 1993; 485-494.

496

497

498

499

500

501

502

503

504

505

506

507

508

509

510

511

512

513

514

515

516

[12] Kavvdas M, Anagnostopoulos A, Kalteziontis N. A framework for the mechanical behavior of the cementer Crinth marl. In Proc Int Sym Geotechnics of Hard Soils - Soft Rocks, Athens: Balkema; 1993; 577-583.

[13] Adachi T, Oka F. An elasto-plastic constitutive model for soft rock with strain softening. Int J Numer Anal Meth Geomech 1995; 19:223-7.

[14] Lagioia R, Nova R. An experimental and theoretical study on the behavior of a calcarenite in triaxial compression. Géotechnique 1995; 45(4): 613-648.

[15] Dieterich JH, Kilgore BD. Direct observation of frictional contacts: new insights for state-dependent properties. PAGEOPH 1994; 143: No. 1/2/3: 283-302.

[16] Hashiguchi K, Ueno M. Elastoplastic constitutive laws of granular materials, Constitutive Equations of Soils. In Proc Int Soc Soil Mech Geotech Eng Spec Ses 9. eds Murayama S, Schofield A N. JSSMFE. Tokyo; 1977; 73-82.

[17] Adachi T, Ogawa T. Mechanical properties and failure criterion of soft sedimentary rock. J. JSCE 1980; 295: 51-63 (in Japanese).

[18] Novello E A, Johnston L W. Geotechnique materials and the critical state. Géotechnique 1995; 45(2): 223-35.

[19] Hicher P Y and Shao J F. Constitutive modeling of soils and rocks. John Wiley \& Sons, 2013

[20] Roscoe K H, Schofield A N, and Thurairajah A. Yielding of clays in state wetter than critical. Géotechnique 1963; 13(3): 211-40. 